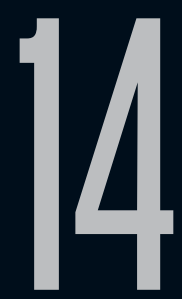

\title{
UMA LEITURA ALEGÓRICA DA UNIFORMIZAÇÃO DAS IDENTIDADES ATRAVÉS DA FIGURA DOS SÓSIAS EM FIGUEIREDO E SARAMAGO
}

Fernanda Martinez Tarran (UEL)

Recebido em 03 set 2017. Fernanda Martinez Tarran é Graduada em Direito (2006) e Aprovado em 24 out 2017. Especialização em Direito Civil e Processo Civil (2008), ambas pela Universidade Estadual de Londrina (UEL). Graduada também em Letras/Inglês (2017) pela Universidade Estadual do Paraná (UNESPAR) - campus Apucarana. Mestre em Literatura Comparada pela Universidade Estadual de Londrina (2017). Atualmente é doutoranda do Programa de Pós-Graduação em Letras - Estudos Literários pela Universidade Estadual de Londrina e trabalha como professora colaboradora na Universidade Estadual do Paraná (UNESPAR) - Campus Apucarana.

Resumo: O presente trabalho pretende proceder a uma leitura alegórica da uniformização das identidades por meio da figura dos sósias em duas obras literárias contemporâneas: "Nos olhos do intruso", de Rubens Figueiredo, e $O$ homem duplicado, de José Saramago. Para isso, começamos por traçar um rápido histórico da mencionada figura literária, passando à análise de elementos do gênero fantástico que cercam o mito do duplo e à interpretação alegórica em torno da questão da identidade. Em seguida, após uma breve retrospectiva da história recente da identidade individual, analisamos o contexto das identidades culturais nos tempos pós-modernos e buscamos, nas 
obras mencionadas, os elementos que se relacionam com o tema. Temos como objetivo mostrar como ambos os textos possuem características comuns que os encaminham à mesma ilustração alegórica.

Palavras-chave: Duplo; Sósia; Identidade; Fantástico.

Abstract: The present work intends to carry out an allegorical reading of the uniformity of identities through the figure of the double in two contemporary literary works: "Nos olhos do intruso", by Rubens Figueiredo, and "O homem duplicado", by José Saramago. With that intent, we begin by tracing a brief history of the aforementioned literary figure, passing to the analysis of some elements of the fantastic genre that surround the myth of the double and proceeding to the allegorical interpretation around the subject of the identity. Then, after a quick retrospective of the recent history of individual identity, we analyze the context of cultural identities in postmodern times and look at some elements in both literary works that relate to the theme. The intention is to show how both texts have common characteristics that lead to the same allegorical illustration.

Keywords: Double; Identity; Fantastic literature.

\section{o SÓSIA}

A temática do duplo vem acompanhando a humanidade há eras. Recurso insistentemente utilizado nos mais variados tipos de relatos e narrativas, a figura do duplo atravessou inúmeros períodos históricos e chegou à contemporaneidade, tendo-se perpetuado com sucesso na mitologia e na literatura. Sobre a presença do duplo nas lendas e mitos, a pesquisadora Nicole Fernandez Bravo afirma:

Aidéia da dualidade da pessoa humana-masculino/ feminino, homem/animal, espírito/carne, vida/ morte - revela uma crença na metamorfose (até 
mesmo na metempsicose) que implica uma certa ideia do homem como responsável pelo seu destino. (2000, p.262)

A figura dos sósias - aqueles que possuem entre si tamanha semelhança física que não é possível diferenciá-los - é frequentemente apontada como uma das primeiras formas do duplo na literatura. Para Bravo, o "gêmeo é aquele que conseguiu tornar visível no mundo seu duplo" (2000, p.264).

Já na Antiguidade clássica, o dramaturgo romano Plauto (ele mesmo um imitador dos gregos) consagrou os sósias em suas comédias Anfitrião e Os Menecmos. Tal é o pioneirismo de Plauto que o próprio termo sósia remonta a Anfitrião. Nessa comédia, o deus Júpiter toma emprestados os traços do protagonista Anfitrião para poder passar a noite com a esposa deste, enquanto o deus Mercúrio assume a identidade do escravo Sósia, de modo a poder dar cobertura a Júpiter na concretização do embuste. Quando os verdadeiros Anfitrião e Sósia retornam da guerra que os fizera ausentes até então, acabam por se deparar com os impostores. Esse é o mote para muitas confusões de identidade. Assim como, com base na obra de Plauto, o termo anfitrião adquiriu o sentido de "aquele que recebe em casa", o termo sósia passou a designar "cópia humana".

Historicamente, as narrativas que envolvem sósias valemse da semelhança física entre duas pessoas para criar confusões e relatar casos de substituição e usurpação de identidade, geralmente servindo à comédia. Não faltam exemplos de retorno ao tema, bastante recorrente até o final do século $\mathrm{XVI}$, quando, graças à concepção unitária do mundo, prevalecia a tendência à homogeneidade nas histórias de duplos (BRAVO, 2000, p.263). 
Shakespeare é o mais célebre dentre os muitos autores que retomaram o tema dos sósias. Em sua Comédia dos erros, uma adaptação de Os Menecmos, de Plauto, ele envolve não somente uma, mas duas duplas de sósias em sucessivas confusões de identidade.

Importa ressaltar que, até este momento, a duplicação aparece tão-somente como uma situação momentânea, que acaba sendo resolvida de modo a permitir que os sósias desfaçam a confusão no final. Em momento algum a identidade dos personagens é colocada em questionamento.

É com o advento do século XVII, quando se estabeleceu a relação binária sujeito-objeto e passou a imperar a concepção dialética do mundo, que o mito do duplo se atrelou ao pensamento da subjetividade (BRAVO, 2000, p.264). Interessa, neste ponto, a definição do crítico literário norte-americano Carl F. Keppler, mencionada por Bravo:

...o duplo é ao mesmo tempo idêntico ao original e diferente - até mesmo o oposto - dele. É sempre uma figura fascinante para aquele que ele duplica, em virtude do paradoxo que representa (ele é ao mesmo tempo interior e exterior, está aqui e lá, é oposto e complementar), e provoca no original reações emocionais extremas (atração/repulsa). De um e outro lado do desdobramento a relação existe numa tensão dinâmica. O encontro ocorre num momento de vulnerabilidade do eu original. (2000, p.263)

Trata-se, aqui, do duplo que se baseia na identidade fragmentada. O tema é frequentemente abordado nas obras que se ocupam do fantástico a partir do século XIX, e é empregado para representar de modo figurado e metafórico os conflitos do 
indivíduo moderno. Bravo afirma que, modernamente, o duplo, mesmo quando representado por um outro que é externo ao original, se caracteriza pela interioridade - ou seja, o conflito que ele representa é de caráter eminentemente psicológico.

Entre as obras que abordam o tema do duplo e dos sósias, a narrativa "William Wilson", de Edgar Allan Poe, é das mais célebres. No conto, vemos o personagem principal às voltas com um sósia que o persegue por anos e que, no final, revela-se uma parte de si mesmo. Através dos recorrentes exemplos fornecidos pela literatura moderna, é possível constatar que o sósia permanece como tema literário do duplo. Porém, na esteira dos tempos modernos, os significados que lhe são atribuídos se tornaram mais diversificados, complexos e multifacetados.

\section{O FANTÁSTICO E A ALEGORIA}

É certo que o mito do duplo, em todas as suas formas e variações, apresenta grande afinidade com o gênero fantástico - e a modalidade dos sósias não é uma exceção.

Segundo Todorov (2008), o discurso fantástico se caracteriza por gerar inquietação através do relato de eventos de aparência sobrenatural e de fatos inexplicáveis por meio de nossas leis naturais. Ao longo da narrativa, tais ocorrências podem acabar sendo atribuídas ao sonho e à imaginação do personagem, bem como podem ser aceitas como parte de fenômenos que nos são desconhecidos. No entanto, o efeito fantástico decorre justamente da hesitação (por parte do leitor e, na maioria dos casos, também do protagonista) diante da natureza estranha do acontecimento sobrenatural. A linguagem fantástica busca sobrepor o inverossímil 
à ordem racional e assim fazer com que o leitor oscile entre uma explicação racional e outra misteriosa; temos, assim, uma narrativa ambígua em que o leitor ideal não chega a um fim conclusivo. Assim, de acordo com Todorov:

O fantástico, como vimos, dura apenas o tempo de uma hesitação: hesitação comum ao leitor e à personagem, que devem decidir se o que percebem depende ou não da "realidade", tal qual existe na opinião comum. (2008, p.47-48)

Apresentamos, aqui, duas obras literárias da modernidade tardia que se utilizam de elementos do fantástico no tratamento do tema do duplo.

O conto "Nos olhos do intruso", de Rubens Figueiredo (2001), fornece um bom exemplo de literatura fantástica. Nele, o narradorprotagonista narra sua própria trajetória a partir do momento em que encontra no teatro uma pessoa igual a si, porém um pouco mais nova. Aos poucos, passa a assumir a identidade de seu sósia numa espécie de amálgama. Ao ser confundido com o duplo, o narrador toma para si a vida e a memória do outro. Quando, por fim, o jovem duplo morre, o protagonista passa a sentir-se ignorado e muda-se para outra cidade, onde conhece um sósia mais velho.

O conto conserva a ambiguidade até o final. A visão parcial proporcionada pela narrativa em primeira pessoa favorece a dúvida. Os fenômenos estranhos não são, em momento algum, elucidados segundo as leis do mundo natural; não há nada no texto capaz de refutar peremptoriamente a existência de um sósia ou a assunção de múltiplas identidades pelo protagonista. Ao mesmo tempo, não se pode ter a certeza de que esses episódios se situam no terreno do sobrenatural, como veremos adiante. 
Primeiramente, ambos os encontros com os duplos se dão em terrenos férteis para a ilusão: o teatro, espaço que alude à fantasia e à transformação, e uma barbearia cercada de espelhos, o que fortalece a possibilidade de que o protagonista estivesse influenciado por sua própria imaginação.

Depois do encontro com o sósia, algumas pessoas passam a relatar ter visto o narrador em locais onde ele não esteve. Diante dessa informação, seu primeiro impulso é a negação, que caracteriza a hesitação do protagonista ante o evento estranho. Após algum tempo, no entanto, ele se resigna a ouvir os relatos em silêncio e passa, pouco a pouco, e sem notar, a dar-lhes crédito.

O texto fornece, entretanto, diversas pistas de que a natureza incomum dos eventos narrados pode ser apenas fruto da imaginação do narrador: "[o]utros talvez não prestassem atenção. Outros talvez não encadeassem uma coisa à outra. Sei que, mesmo na vida mais banal, há lugar para tudo" (FIGUEIREDO, 2001, p.541). São coincidências, acontecimentos comuns e fortuitos, mas o protagonista enxerga desdobramentos, uma continuação a partir do primeiro evento, um sistema. No momento em que ele já se considera detentor de múltiplas identidades, passa a cumprimentar estranhos na rua, acreditando que será reconhecido:

Arrisquei cumprimentar alguém que eu, com absoluta certeza, não conhecia. Após um instante de surpresa bem natural, [...] a pessoa respondeu ao meu cumprimento, de forma discreta. Sua expressão deu a entender que, naquele momento, não tinha tempo para conversar comigo como gostaria, e seguiu adiante. (FIGUEIREDO, 2001, p.542) 
Essa passagem pode ser vista como a descrição de um fato totalmente corriqueiro. Uma pessoa é cumprimentada por um desconhecido; reage com surpresa e, em seguida, ao perceber que foi confundida, tenta amenizar o mal-entendido educadamente, com um discreto cumprimento, desvencilhando-se da situação embaraçosa o mais rapidamente possível.

O narrador pode, portanto, estar distorcendo o significado de acontecimentos cotidianos de modo a extrair deles significados outros que corroborem a existência de um sósia cuja vida se comunicaria com a sua própria, agregando sentido a ela e expandindo-a.

Assim, ainda que o protagonista tenha passado a acreditar na essência sobrenatural dos fatos que o rodeiam, o leitor continua a hesitar. Persistem a dúvida e a perplexidade típicas do fantástico.

Na obra de Saramago, entretanto, o fantástico não sobrevive incólume até o fim da história. Em O homem duplicado (SARAMAGO, 2002), o autor vale-se de elementos do gênero fantástico para construir um ambiente de tensão e certo mistério, ao passo em que vai revelando mais detalhes sobre a existência de um suposto sósia do professor de História Tertuliano Máximo Afonso.

Afinal, se, segundo Todorov (2008), o gênero fantástico é aquele em que assistimos a um evento sobrenatural, estranho às leis conhecidas, que gera hesitação e dúvida, temos todos esses elementos presentes na primeira fase do romance, uma vez que a suspeita da existência de um sósia idêntico ao protagonista em todos os mínimos detalhes físicos (e até mesmo na data de nascimento) é algo sobremaneira espantoso e extraordinário. Até que o protagonista o encontre pessoalmente, subsiste a dúvida em 
torno de sua existência - e da magnitude de sua semelhança física -, o que cria uma sensação de suspense.

Apesar disso, com o desenrolar da história, tal dúvida se extingue, já que a existência de um sósia é comprovada não somente pelos próprios duplicados, mas por suas respectivas companheiras. Confirma-se a natureza sobrenatural do evento. Poderíamos, com isso, querer situar a obra no terreno do maravilhoso, mas o mundo descrito por Saramago é excessivamente realista, banal e cotidiano - o que leva a crer que os elementos sobrenaturais presentes na obra não foram ali colocados com a intenção de evocar um universo distinto do nosso, mas de provocar uma interpretação alegórica (TODOROV, 2008, p.39-40).

Além disso, não se pode ignorar o fato de que o texto contido nas abas da edição de $O$ homem duplicado (SARAMAGO, 2002), aqui utilizado como referência, explicita o significado alegórico a ser atribuído ao romance que o leitor tem nas mãos. O texto em questão esclarece que, ao compor a história, Saramago quis tocar "num dos aspectos mais desumanos da sociedade global, que, em sua ânsia uniformizadora, dissolve as singularidades numa cultura pretensamente universal" (2002).

Outra evidência que reforça a inclinação por uma explicação alegórica está no conjunto da obra do autor. Os romances recentes de Saramago retratam uma época de transformações que, para boa parte da humanidade, resulta em mais perdas que ganhos. Exemplos são Ensaio sobre a cegueira, cujos personagens perdem a visão, em uma alusão a um tempo em que todos parecem estar cegos, e A caverna, que traz artesãos que perdem seus empregos por não conseguirem sobreviver à sociedade de consumo. 
Em O homem duplicado, o que está realmente em tela é a perda de identidade em uma sociedade que cultiva a individualidade, mas, paradoxalmente, estabelece padrões estreitos de conduta e de aparência. É uma parábola da padronização que sofremos no mundo globalizado, e como ela conduz à perda de identidade.

A mesma interpretação pode ser estendida ao conto de Figueiredo, já que o problema da identidade é o cerne da narrativa - o que se evidencia na personalidade fragmentada do protagonista e no fato de que os personagens não têm nome.

O sujeito de "Nos olhos do intruso" não se concebe como uma unidade; pelo contrário, ele se afasta tanto de uma unidade que acaba por se transformar em um outro. Através da duplicidade, o narrador acrescenta outras identidades à sua identidade em crise. Ao abrir mão de uma personalidade nuclear, ele passa a viver o outro, e a ser, ao mesmo tempo, vários e nenhum.

Os simulacros de que se vale o autor são alternativas para ilustrar o caráter insubstancial de vidas inautênticas. Ele busca figurar o vazio e a pluralidade atuais, visto que uma das marcas da identidade pós-moderna é exatamente a falta de um centro identitário único, como será demonstrado adiante.

\section{BREVE HISTÓRICO DA IDENTIDADE INDIVIDUAL}

As características culturais de classe, gênero, sexualidade, etnia, raça e nacionalidade, que antes nos forneciam um sólido posicionamento acerca de nossa própria identidade, vêm sofrendo contínuas mudanças nos tempos modernos. Por consequência, a identidade do homem pós-moderno também passa por uma crise de definição. 
Segundo Stuart Hall (2006, p.10-13), o conceito de sujeito moderno mudou em três pontos estratégicos durante o período que constitui para ele a modernidade, como veremos a seguir.

Antes do advento do humanismo renascentista, no século XVI, o conceito de individualidade estava firmemente atrelado à tradição e à ordem divina que regia todas as coisas. Uma pessoa não podia ser um indivíduo soberano - sua posição e seu status se submetiam a uma ordem estável, inalterável e indiscutível.

O século XVI marcou o início do colapso da ordem social, econômica e religiosa medieval, bem como o surgimento do sujeito moderno. Muitos movimentos contribuíram para alterar essa visão do indivíduo: o fim da rígida hierarquia da sociedade feudalista, o que permitiu uma nova ênfase na existência pessoal do indivíduo; as reformas protestantes, que abalaram a mediação da relação entre homem e deus pela igreja e permitiram que passasse a responder diretamente a Deus; o humanismo, que colocou o homem no centro do universo e foi seguido pelo iluminismo, que propagou o ideal de homem racional, científico, liberto de dogmas; e as revoluções científicas, que deram ao ser humano a capacidade de investigar e decifrar os mistérios naturais.

Assim, no iluminismo, o sujeito passou a ter como atributos a razão e uma identidade unificada, um núcleo autônomo que se desenvolvia conforme o indivíduo atravessava as fases da vida - sua essência, no entanto, permanecia a mesma.

Até o século XVIII, portanto, a vida estava centrada no indivíduo possuidor da razão. Porém, conforme as sociedades modernas se tornavam mais complexas, elas adquiriam uma forma mais coletiva 
e social. Surgiam as estruturas do estado-nação e as grandes massas que viriam a compor as democracias modernas; depois da industrialização, as formações de classe, o desenvolvimento do capitalismo moderno e o surgimento dos conglomerados empresariais da nova economia fizeram emergir uma concepção mais social do sujeito, em que o indivíduo é considerado parte da coletividade que sustenta as novas estruturas.

Dessa forma, a concepção sociológica veio para alterar os conceitos anteriores, sugerindo que a identidade de um indivíduo não é autossuficiente; constitui-se a partir de sua relação com o ambiente e seus atores, por meio dos quais ocorre uma mediação de valores, sentidos e símbolos culturais. Assim, para os adeptos desta concepção, a identidade é produto da interação entre o núcleo identitário do individuo e o cenário social. A identidade faz a ligação entre o mundo pessoal, interior, e o mundo público, exterior, numa relação ainda unificada, estável e previsível.

\section{A IDENTIDADE PÓS-MODERNA}

A pós-modernidade (período posterior à segunda metade do século $X X)$ vem desestruturando as bases sólidas em que costumava se apoiar a identidade. Como conseqüência de mudanças estruturais e institucionais, os elementos culturais estão sofrendo modificações, e o próprio sujeito tornou-se fragmentado. Assim, se a relação entre sujeito e elementos culturais está mais precária, estabelecer uma identidade com base nesse cenário tornouse problemático e contraditório. O sujeito foi descentralizado, resultando nas identidades abertas, variáveis e inacabadas do sujeito pós-moderno. 
Há consenso entre muitos estudiosos do tema (ainda que com divergência de nomenclatura) a respeito da descontinuidade, fragmentação, ruptura e deslocamento que vêm sofrendo as instituições modernas. Essa desagregação e o deslocamento da concepção de indivíduo se deu por uma série de rupturas nos discursos do conhecimento. Alguns descentramentos principais tiveram efeitos profundamente desestabilizadores sobre as ideias da modernidade tardia e, particularmente, sobre a forma como o sujeito e a questão da identidade são concebidos (HALL, 2006, p.26). Veremos alguns deles a seguir.

A descoberta do inconsciente, que funciona em uma lógica diferente daquela da razão, resultou dos estudos do psicanalista Sigmund Freud e fez ruir o conceito de homem cartesiano, racional, consciente, que só crê naquilo que vê. O trabalho de Freud permitiu que surgisse uma nova visão acerca do indivíduo e de seu comportamento social.

O linguista Ferdinand de Saussure, pai da linguística estrutural, por sua vez, afirmou que a língua é um sistema social que exprime os significados já embutidos em nosso sistema cultural, tirando do indivíduo a autoria total de seus enunciados. Segundo o teórico, a capacidade de comunicação só se desenvolve plenamente em sociedade, o que faz com que a presença do outro seja vital.

Há uma reinterpretação do pensamento marxista que, de certo modo, permite uma leitura do homem como um ser social, que depende das condições à sua volta para construir a história. De acordo com esse pensamento, o indivíduo só é capaz de galgar grandes degraus se calcado nas vitórias conquistadas por aqueles que o antecederam. 
Por fim, citemos as teorias de Foucault sobre a genealogia do sujeito moderno e sua visão sobre o poder como uma força ao alcance de todos, presente dentro de cada grupo social, e não mais como algo restrito ao Estado; e o impacto do feminismo enquanto crítica teórica e movimento social.

Nas sociedades tradicionais, os valores e símbolos oriundos do passado são valorizados e passados adiante com o intuito de perpetuar o conhecimento das gerações anteriores; a sociedade se fundamenta em práticas sociais recorrentes e estáveis. A modernidade é marcada pela mudança nessa dinâmica: novas informações surgem a todo tempo e de todas as direções, as práticas sociais passam a ser constantemente reexaminadas e reformuladas, a experiência da mudança passa a ser corrente, rápida e contínua, e a vida torna-se mais reflexiva.

Como disse Marx, a modernidade

é o permanente revolucionar da produção, o abalar ininterrupto de todas as condições sociais, a incerteza e o movimento eternos (...). Todas as relações fixas e congeladas, com seu cortejo de vetustas representações e concepções, são dissolvidas, todas as relações recém-formadas envelhecem antes de poderem ossificar-se. Tudo que é sólido se desmancha no ar... (MARX; ENGELS, 2013, p.81)

Outro fator que torna as transformações da modernidade ainda mais velozes e impactantes que aquelas dos períodos anteriores é o seu alcance: com a globalização, as mais variadas e distantes regiões do planeta são colocadas em conexão, o que possibilita que a transformação que tem origem num ponto atinja qualquer outro ponto na superfície do globo. 
A crescente interdependência global está produzindo uma fragmentação de códigos culturais, uma multiplicidade de estilos, uma ênfase no efêmero, na diferença e no pluralismo cultural - em escala mundial.

Podemos ver que as sociedades contemporâneas caracterizamse por ter deslocado aquele que era antes o centro unificado, e em seu lugar não surge um novo centro, mas uma pluralidade deles. Não há princípio organizador e articulador único nem uma só regra. Caracterizam-se pela diferença, pelos antagonismos, pela variedade de elementos culturais (HALL, 2006, p.17).

O crítico literário Terry Eagleton (1998) se manifestou de forma parecida sobre a era que ele denomina pós-moderna. O autor define o termo pós-modernidade como um conjunto de ideias que veio confrontar os conceitos clássicos de razão e verdade, as grandes instituições e, acima de tudo, a identidade sólida e inabalável defendida pelos iluministas. Assim, a noção de sujeito pós-moderno de Eagleton conduz a um panorama em que o indivíduo se encontra em plena crise de identidade. O sujeito, até então ilustrado como uma identidade una e invariável, tornouse fragmentado, constituído não por uma única, mas por uma multiplicidade de identidades.

Conforme a vida social vai sendo influenciada pelo mercado global de estilos e lugares, pelas imagens da mídia e pelos sistemas de comunicação mundialmente interligados, as identidades antes conectadas a estilos, lugares, histórias e tradições específicos vão se desvinculando de suas origens e passam a flutuar livremente.

Os fluxos culturais, entre as nações, e o consumismo global criam possibilidades de "identidades 
partilhadas" - como "consumidores" para os mesmos bens, "clientes" para os mesmos serviços, "públicos" para as mesmas mensagens e imagens - entre pessoas que estão bastante distantes umas das outras no espaço e no tempo. (HALL, 2006, p.74)

Surgem identidades múltiplas, politizadas e passíveis de variação de acordo com a circunstância que se apresenta. Não há mais uma identidade única e suprema que possa abarcar as demais, abrangendo todas as pessoas ou um grupo grande delas.

Somos confrontados por uma gama de diferentes identidades (cada qual nos fazendo apelos, ou melhor, fazendo apelos a diferentes partes de nós), dentre as quais parece possível fazer uma escolha. [...] Foi a difusão do consumismo, seja como realidade, seja como sonho, que contribuiu para esse efeito de "supermercado cultural". No interior do discurso do consumismo global, as diferenças e as distinções culturais, que até então definiam a identidade, ficam reduzidas a uma espécie de língua franca internacional ou de moeda global, em termos das quais todas as tradições específicas e todas as diferentes identidades podem ser traduzidas. Este fenômeno é conhecido como "homogeneização cultural". (HALL, 2006, p.75)

Vivemos, assim, na era da informação e do imediatismo. O mundo contemporâneo é o mundo das imagens, a sociedade do espetáculo. A televisão e os meios multimídia são, ao mesmo tempo, produtos e produtores; produtos do capitalismo e agentes na promoção da cultura de consumo. Exercem um extenso poder sobre as massas, gerando um estado de alienação (FERNANDES, 2009, p.306). 
Saramago talvez tivesse isso em mente quando situou o primeiro encontro de Tertuliano com seu duplo justamente no momento em que o protagonista assiste a um filme bê "produtos rápidos para consumo rápido que não aspiram a mais que entreter o tempo sem perturbar o espírito" (SARAMAGO, 2002, p.88).

Outra característica de nossos tempos é a massificação e a padronização. O mercado obtém lucro a partir de uma realidade em que as pessoas querem e gostam das mesmas coisas. Tanto maior é o lucro quanto mais padronizados são os gostos dos consumidores (FERNANDES, 2009, p.306).

Perfeito exemplo da massificação pós-moderna é a pop art de Andy Warhol, com suas imagens do universo pop repetidas à exaustão. Nesse sentido,

a fotografia desempenha um papel pós-moderno ao apresentar a questão da originalidade tão debatida no contemporâneo, já que 'podem ser feitas infinitas impressões igualmente bem definidas de um único negativo' e, assim, 'não existe o original, condição que se ajusta perfeitamente à negação pós-moderna da exclusividade e da originalidade'. (HEARTNEY, Apud FERNANDES, 2009, p.311)

Walter Benjamin também trata da questão da reprodutibilidade. Segundo ele, a exaustiva reprodução retira a autenticidade da cópia: "[n]a medida em que [a técnica] multiplica a reprodução, substitui a existência única da obra por uma existência massiva" (BENJAMIN, 2012, p.183).

Em suma, todas as transformações e fenômenos mencionados até aqui contribuíram para uma mudança de perspectiva em que 
o indivíduo unificado, de identidade fixa e consolidada, dá lugar ao homem moderno e sua identidade fragmentada.

\section{OS SÓSIAS PÓS-MODERNOS EM FIGUEIREDO E SARAMAGO}

O Tertuliano de Saramago é um retrato do homem contemporâneo, desmantelado por uma rotina massacrante que é igual todos os dias. A repetição é uma constante em sua vida. Recorre a jogos de sorte para escolher sua refeição, geralmente composta por uma lata de comida congelada ou o prato de costume no restaurante habitual. Entediado pelo trabalho, o trânsito e as ocupações do dia-a-dia em uma cidade de cinco milhões de habitantes, Tertuliano resiste a experimentar coisas novas - de uma iguaria diferente no jantar ao cinema de ficção científica.

Logo nos primeiros capítulos do romance, o protagonista deixa entrever seu caráter conformado de professor regular, que corrige os exercícios de seus alunos "sempre que atentem perigosamente contra as verdades ensinadas ou se permitam excessivas liberdades de interpretação" (SARAMAGO, 2002, p.15). A História de que se encarrega Tertuliano, é, inclusive, comparada a um bonsai a que de vez em quando se aparam as raízes para que não cresça. Interessante é o fato de ser o protagonista um professor de História - uma clara ironia ao imediatismo, que faz com que vivamos sempre no presente e apaguemos o passado, com a perda da noção de História como uma de suas conseqüências.

Sua relação com as mulheres é mais um indicador de sua personalidade indolente, insegura e de sentimentos transitórios. Tertuliano é um fracasso no amor: divorciou-se sem saber por quê, conquistou o amor de uma nova mulher, mas rejeita a idéia 
de um envolvimento mais profundo. Nunca teve as rédeas de seus relacionamentos, no entanto; numa clara demonstração de passividade, deixa-se sempre levar por suas companheiras.

Temos aqui a ilustração da homogeneização moderna: a falta de um centro identitário único, a padronização e a repetição acarretam a dúvida, a flutuação e o questionamento da identidade. A massificação faz com que o sujeito perca a noção da própria individualidade. O eu perde-se, confunde-se com o outro, fragmenta-se.

Eis que a descoberta de um sósia idêntico a si mexe com ele, alterando seu comportamento. Tertuliano, que já oscilava quanto à própria identidade e ao sentido de sua existência, passa por uma transformação. Ter a identidade colocada definitivamente em dúvida o faz buscá-la, lutar por ela.

Ambos os protagonistas de que tratamos aqui acidentalmente descobrem não serem mais pessoas únicas no mundo. A consciência da existência de um sósia, um duplicado, faz com que a individualidade desapareça; assim, ambos perdem a identidade. Esse discurso reforça o valor da singularidade, da originalidade e da autenticidade.

O duplo aqui considerado tem muito dos elementos citados por Clément Rosset, para quem o sujeito não teme a morte, mas a própria inexistência, a própria inautenticidade. 0 medo dominante é o da falta de originalidade: "o real não está do lado do eu, mas sim do lado do fantasma: não é o outro que me duplica, sou eu que sou o duplo do outro" (ROSSET, 2008, p.88). Nesse sentido, Rosset prossegue:

Pensava-se tratar como original, mas na realidade só se havia visto o seu duplo enganador e tranquilizador; eis de súbito o original em pessoa, que zomba e se revela ao mesmo tempo como o outro e o verdadeiro. 
Talvez o fundamento da angústia, aparentemente ligado aqui à simples descoberta que o outro visível não era o outro real, deva ser procurado num terror mais profundo: de eu mesmo não ser aquele que pensava ser. $(2008$, p.92)

Esse temor do protagonista fica claro no romance de Saramago:

A Tertuliano Máximo Afonso desassossega-o agora a possibilidade de ser ele o mais novo dos dois, que o original seja o outro e ele não passe de uma simples e antecipadamente desvalorizada repetição. (SARAMAGO, 2002, p.174)

O protagonista de Figueiredo também experimenta "o temor de estar sendo sorrateiramente substituído" (2001, p.540) - e acrescente-se ainda o agravante de que seu sósia lhe parecia ser "um pouco mais novo" (2001, p.540).

Ressaltemos que ambas as obras tratam não apenas de uma duplicação, mas de uma multiplicação de identidades. O leitor de O homem duplicado é apresentado a Tertuliano Máximo Afonso, a Antonio Claro, e ainda a um terceiro - incógnito - que surge no final da trama. E não podemos nos esquecer de Daniel Santa-Clara, o duplo de Antonio Claro em sua profissão de ator - ocupação que, providencialmente escolhida para figurar nessa história, traz à baila uma forma institucionalizada de representação do papel alheio e tomada da aparência do outro.

A multiplicidade de identidades em "Nos olhos do intruso" serve ao mesmo fim. O narrador, de vida vazia e carente de sentido, mistura a história e identidade próprias às de seu sósia:

Tudo ia se incorporando à minha memória. 0 meu passado se expandia (...), o meu presente 
também se ampliava, numa espécie de movimento de conquista. Minha vida abarcava muitas outras vidas e assim eu conseguia me sentir mais vivo do que nunca. (FIGUEIREDO, 2001, p.542)

A partir da ciência da morte de seu duplo, ele perde a sensação de multiplicidade e, com isso, uma parte de sua identidade e de sua vida. O protagonista volta a cair no vazio e na falta de sentido de sua rotina pós-moderna e só se recupera quando tem a oportunidade de encontrar um novo sósia.

A idéia de ciclo - inerente à sociedade de consumo e à padronização que lhe é característica - também se faz presente nas duas obras aqui discutidas. O romance de Saramago, que tem a repetição como tema tão destacado, deixa perceber no final um ciclo, uma constante: ainda que um duplo assuma o lugar do primeiro, veremos surgir um terceiro para perpetuar o ciclo. O conto de Figueiredo expõe exatamente o mesmo raciocínio, uma vez que o jovem sósia do narrador morre e acaba sendo sucedido por outro. $\mathrm{O}$ trecho a seguir traz implícita essa ideia de ciclo, repetição infinita e destino inexorável:

Sei agora por que vim para esta cidade. O olhar admirado do homem na barbearia foram as boasvindas e também uma despedida para mim. Já posso sentir o calor das chamas estalando. Mas, até que chegue a minha vez, esse sujeito ainda vai ouvir falar muito de mim. (FIGUEIREDO, 2001, p.543)

Agora, no entanto, trata-se de um sósia mais velho que o protagonista - o que revela um cenário em que as cópias tendem a ser eliminadas, de modo que reste, um dia, apenas o original.

Assim, mais do que registrar um momento histórico no qual todos, ao tomarem parte de um movimento de globalização, 
perdem a identidade e se confundem em uma massa multiforme, as obras literárias aqui analisadas marcam a essência de um mundo regido pela troca de caráter, pela pluralidade de eus que coabitam um único eu recalcado e insatisfeito. Além disso, ilustram o paradoxo existencial do ser humano contemporâneo, que, tomado por um impulso mimético, procura fora de si o que só poderá ser encontrado nele mesmo.

Dessa forma, a leitura aqui realizada revela que a solução para a crise dos tempos modernos está dentro de cada um, e não no outro. O eu só será capaz de encontrar seu lugar se conseguir conferir valor único à própria existência, desvinculando-se dos modelos e padrões que o cercam.

\section{REFERÊNCIAS}

BENJAMIN, Walter (2012). "A obra de arte na era de sua reprodutibilidade técnica". In: Magia e técnica, arte e política: ensaios sobre literatura e história da cultura. São Paulo: Brasiliense. p.179-212.

BRAVO, Nicole Fernandez (2000). "Duplo". In: BRUNEL, Pierre. Dicionário de Mitos Literários. Rio de Janeiro: José Olympio. p.261-288.

EAGLETON, Terry (1998). As ilusões do pós-modernismo. Rio de Janeiro: Zahar. FERNANDES, Gisele Manganelli (2009). "O Pós-Modernismo". In: BONNICI, Thomas (Org.). Teoria Literária: abordagens históricas e tendências contemporâneas. Maringá: Eduem. p.301-318.

FIGUEIREDO, Rubens (2001). "Nos olhos do intruso". In: MORICONI, Ítalo (Org.). Os cem melhores contos brasileiros do século. Rio de Janeiro: Objetiva. p.540-543. HALL, Stuart (2006). A Identidade Cultural na Pós-Modernidade. Rio de Janeiro: DP\&A.

MARX, Karl; ENGELS, Friedrich (2013). "Manifesto do Partido Comunista". In: BOTELHO, André (Org.). Essencial sociologia. São Paulo: Penguin Classics Companhia das Letras. p.77-117. 
PLAUTO (1993). Anfitrião. Lisboa: Edições 70.

POE, Edgar Allan (2000). "William Wilson". In: Poesia e prosa: obras escolhidas novelas, contos, colóquios, poemas, ensaios. Rio de Janeiro: Ediouro.

ROSSET, Clément (2008). O real e seu duplo: ensaio sobre a ilusão. Rio de Janeiro: José Olympio.

SARAMAGO, José (2002). O homem duplicado. São Paulo: Companhia das Letras. (2001). A caverna. São Paulo: Cia. Das Letras. (1995). Ensaio sobre a cegueira. São Paulo: Cia. Das Letras.

TODOROV, Tzvetan (2008). Introdução à Literatura Fantástica. São Paulo: Perspectiva. 